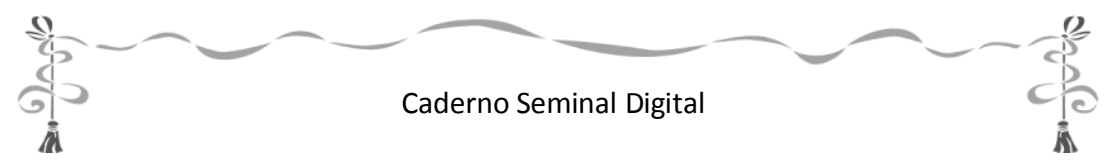

\title{
REFLEXÕES SOBRE OS ASPECTOS LEXICAIS NA FALA DO SERTANEJO DO SUL DO MARANHÃO ${ }^{30}$ \\ REFLECTIONS ON ASPECTS LEXICAL TALKING SERTANEJO SOUTH MARANHÃO
}

Maria Célia Dias de Castro

UEMA/CESBA

Resumo: Este trabalho tem como objetivo discorrer sobre alguns processos da dinâmica léxica na formação e alteração de itens lexicais do sertanejo do Sul do Maranhão. São apresentados aspectos sócio-históricos dessa região e o processo de formação do léxico, no que diz respeito aos fenômenos morfofonêmicos e morfossemânticos da língua.

Palavras-chave: itens lexicais, história, formação do léxico.

Abstract: This paper aims to discuss some processes of the lexical dynamics in the formation and or alteration of lexical items to the backcountry of the south region of Maranhão. Aspects of the history of the region are presented and the processes of formation of the lexicon and the sociohistorical, with regard to the phenomena of morfhofonological and the morfhossemantic aspects of the language.

Keywords: lexical items, history, training lexicon.

\section{INTRODUÇÃO}

Esta pesquisa pretende fazer uma reflexão acerca de alguns processos motivadores da criação, aquisição e alteração que ocorrem nas formas léxicas peculiares do falar

\footnotetext{
${ }^{30}$ Trabalho apresentado como avaliação final da disciplina Morfologia, do Programa de Pós-Graduação em Letras e Linguística da Universidade Federal de Goiás, Goiânia-GO.
}

Caderno Seminal Digital Ano 19, no 19, V. 19 (Jan-Jun/2013) - ISSN 1806-9142

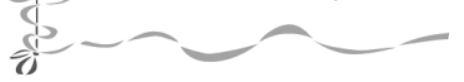

182

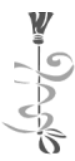


Caderno Seminal Digital

(1)

local da região Sul do Maranhão e apresentar algumas relações entre o léxico e os níveis fonológico e morfológico da língua.

Para atender às transformações ou novas necessidades com que se depara no seu ambiente linguístico, muitas vezes distante dos termos que preencheriam essas abstrações, o sertanejo vai-se utilizando de novos termos ou criando outros, como também dá novos significados a termos já existentes.

\section{A FORMAÇÃO HISTÓRICO-CULTURAL DO SERTANEJO}

A colonização da região Sul do Maranhão, conhecida na época como Pastos Bons, ocorreu de forma tardia em relação às do litoral maranhense, na segunda metade do Século XVIII. Vaqueiros pernambucanos e baianos por aqui adentravam, utilizando-se do sistema de Bandeiras, grupos de guerra que se compunham de centenas de homens, munidos com armas de fogo, com o objetivo de afugentar os povos indígenas habitadores do sul do Estado. Eles fizeram incursões margeando os rios que banham esta região, pelos rios Neves, Balsas e Macapá, à procura de terras para a criação do gado.

Nesse processo, fundaram vilas e dizimaram muitas tribos. Dentre essas, foram os Pimenteira ${ }^{31}$, os Gueguê e os

\footnotetext{
31 Esclarecemos que a escrita dos nomes dos povos indígenas e de suas respectivas línguas, utilizada neste trabalho, segue a convenção de 1953, promovida pela Associação Brasileira de Antropologia, atualmente adotada pela grande maioria de antropólogos, linguistas, missionários e pelos próprios indígenas. O ponto principal
}

Caderno Seminal Digital Ano 19, no 19, V. 19 (Jan-Jun/2013) - ISSN 1806-9142

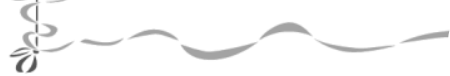

183

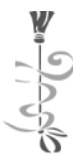


Acoroá que resistiram às invasões por mais tempo, numa luta sangrenta pela manutenção da terra e da cultura (CABRAL, 1992). Entretanto, em 1758, os bandeirantes conseguiram o aldeamento dos Acoroá, na aldeia de São Félix de Balsas, enquanto outros Acoroá e Gueguê haviam sido aldeados na missão de São Gonçalo, no Piauí. Ribeiro (2002 [1815; 1819; 1819]) nos informa que conheceu essa aldeia no início do Século XIX. Segundo ele, nesta região viviam mais de oitenta mil índios, conhecidos como Timbira ${ }^{32}$. Nesse período, aquele aldeamento já se encontrava em declínio e a frente de vaqueiros aprisionara e afugentara os indígenas das campinas para ceder lugar à civilização do couro (CABRAL, 1992). Dessa forma, misturou-se a base humana da região, a princípio, os remanescentes índios do grupo Timbira com os bandeirantes vaqueiros nordestinos (da Bahia e Pernambuco); posteriormente, alguns escravos trazidos da região litorânea maranhense, ou fugidios do sistema escravagista. O sertanejo da região de Balsas, "caboclo", continuou sua mestiçagem da mistura de alguns remanescentes dos escravos com os retirantes nordestinos das secas do final e início dos Séculos XIX e XX, principalmente dos estados do Ceará e do Piauí. A

dessa convenção que aqui seguimos é “os nomes de povos (e de línguas) indígenas serão empregados como palavras invariáveis, sem flexão de gênero nem de número: a língua Boróro (e não Boróra), os índios Boróro (e não Boróros)" (RODRIGUES, 1986, p. 10). Esses nomes serão escritos em letras maiúsculas. ${ }^{32} \mathrm{O}$ antropólogo Darci Ribeiro (1986) informa que teria havido mais de duzentos mil índios, dos quais sobreviveram os Canela, os Krikati, os Gaviões e os Khrahô.

Caderno Seminal Digital Ano 19, no 19, V. 19 (Jan-Jun/2013) - ISSN 1806-9142
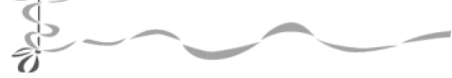
partir da década de setenta (Século XX), chegaram agricultores gaúchos à procura de terra para o plantio no sistema mecanizado.

Há, pois, grande diversidade étnica que influenciou a formação histórica e cultural do nosso sertanejo, em que esse sincretismo cultural, sem dúvida, marcou a língua, no seu processo de formação. Assim, a história que constitui o homem sertanejo e a sua cultura é a própria história constitutiva dos falares regional e local. Para ilustrar essas marcas no discurso do sertanejo, utilizamo-nos do corpus levantado, por meio de entrevistas gravadas, para a nossa dissertação de mestrado (CASTRO, 2008), do qual deriva nossa análise.

\section{ANÁLISE DOS DADOS}

As duas funções primárias da linguagem humana, segundo Givón (2001), são a representação e a comunicação do conhecimento. Esta, dividida em dois subsistemas: de representação e de codificação cognitiva. O sistema de representação cognitiva compreende 0 nível léxicoconceptual, o da informação proposicional e o do discurso multiproposicional. O nível léxico-conceptual, segundo esse autor, é um repositório de conceitos estáveis no tempo, em que o fluxo do conhecimento é gradual; no compartilhamento social, em que as palavras possuem o mesmo significado para todos os membros de uma comunidade de fala; e como bem-

Caderno Seminal Digital Ano 19, no 19, V. 19 (Jan-Jun/2013) - ISSN 1806-9142
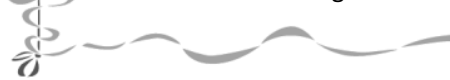

185

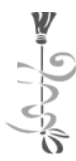


codificado, em que o conhecimento lexical é apresentado associado com seus próprios rótulos de códigos perceptuais, constituindo um mapa cognitivo do nosso universo linguístico experiencial, organizado como uma rede semântica de nódulos e conexões.

Considerando essa rede semântica (GIVÓN, 2001), analisamos os itens lexicais sob as perspectivas da dinâmica sistemática, histórica e sociocultural. Primeiramente, apresentamos os grupos e respectivos subgrupos, com esclarecimentos acerca de cada um. Em seguida, os itens lexicais, com o significado e a etimologia extraídos do Houaiss e Vilar (2001), doravante HV2001. Especificamos o significado depreendido no ambiente linguístico original e discorremos acerca dos processos da dinâmica lexical.

Itens lexicais sob a perspectiva da dinâmica sistemática da língua

Esses processos morfológicos envolvem a mudança/recriação das formas existentes no plano intraléxico, em que há a eliminação, a alteração ou a inserção de segmentos vocálicos ou consonantais na raiz de formas já existentes, com repercussão ou não no significado destas formas. Identificadas essas ligações, passa-se a estudar a relação constitutiva das formas existentes, a estrutura morfológica e semântica que subjazem à constituição do item lexical e, a partir de então, a identificar a formação de unidades mínimas significativas, os morfemas e as palavras.

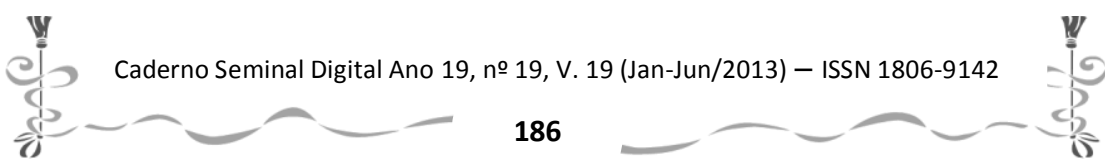


a

\section{Caderno Seminal Digital}

Além desses, influenciam esses processos os fatores semânticos e pragmáticos (AIKHENVALD, 2007).

b) Inventário de itens que apresentam mudanças fonéticofonológicas

A sistematicidade do contexto fônico é o responsável pelas alterações que se processam na forma em virtude de motivações como a posição na sílaba ou no vocábulo, as condições do acento, o ambiente determinado por outros fonemas, processos de assimilação/dissimilação, maneira como o fonema se liga ao que se the segue.

\section{Carcamanjo}

Mudubim: Pois'é. Qui era do finadu Zé Vicenti, irmãu de Salumãu Carcamanju.

HV2001: carcamano substantivo masculino (1867); indivíduo nascido na Itália, macarrone. Indivíduo de origem árabe. Engraxate, vendedor ambulante. Etimologia de origem duvidosa.

[O termo refere-se a estrangeiros, vindos principalmente de países do oriente.]

[Em carcamanjo, há a alteração da forma fônica, com um processo de dissimilação, com a alteração da nasal $/ \mathrm{n} /$ e a inserção do fonema palato-alveolar /3/, em virtude de o ambiente da última sílaba ser influenciado pela existência de fonemas nasalizados da silaba precedente, passando aquela a ter um aspecto palatal ou "molhado" em vez de nasal.]

Caderno Seminal Digital Ano 19, no 19, V. 19 (Jan-Jun/2013) - ISSN 1806-9142 


\section{Cumbuero}

Neuza: U meu pai era u cumbueru daqui di cima.

HV2001: Adjetivo substantivado (1734); aquele que comboia. Comboio é substantivo masculino (1654); conjunto organizado de veículos que transportam mercadorias, víveres, utensilios, pessoas etc. para um mesmo lugar sob a guarda de uma escolta; conjunto de animais ou pessoas que se deslocam próximos uns aos outros, demandando um mesmo destino; tropa de bestas de carga que levam gêneros e mercadorias. Etimologia francesa: convoi; derivado do latim popular conviare, ir pela estrada.

[Comboieiro é, na linguagem do sertanejo, o vendedor de mercadorias que não tinha propriamente um comércio estabelecido, mas também não tinha função como a atual de um camelô. Esse personagem comprava as mercadorias em quantidade suficiente, por um determinado período, para abastecer certa "redondeza".]

[Em cumbueru (comboieiro), há o alçamento do traço de altura do fonema /o/, facilitado pela posição pretônica (influência do acento) e monotongação do ditongo ei.]

\section{Invanti}

Mudubim: Vamu prantá só di janeru invanti qui aí é terra seca.

HV2001: O mesmo que em vante, significa "em diante, de janeiro em diante (1655)". Uso mais empregado nas locuções 
levar à vante. Levar à frente do navio, entre a caverna mestre e a roda de proa. À proa, na proa.

[Em invanti há o alçamento ${ }^{33}$ da primeira vogal, motivado pela assimilação do traço de altura do /i/ da última sílaba, além da junção da preposição para desfazer a locução adverbial.]

\section{Tcheus}

Mudubim: -Mininu, tu rá ta estudanu mininu?Rapaiz, vai cuidá di tcheus inguentu pá chegá im tcheu horáriu mininu!

HV2001: Teu, pronome possessivo que determina um substantivo (coisa ou pessoa) (s. XIII); que é relacionado às pessoas a quem se fala (segunda pessoa do singular), significando: pertence à, ou próprio da, ou provocando ou sentido pela pessoa a quem ou com quem se fala: a ti, de ti, por ti. Que te compete ou te é devido; que te cabe. Etim. latim: tuus, tua, tuum, tuum; teu tua.

[Tcheus é o mesmo que teus.]

[No pronome possessivo tcheus há a africação do /t/ diante de /e/, facilitada pelo ambiente fonológico, que é a tendência de o /t/ tornar-se uma africada diante de /i/ e, menos comumente, diante de /e/. Também ocorre com esse pronome diante de /a/ Tchas coisas, e de /o/tcho pai.]

c) Inventário com processos de truncamento

${ }^{33}$ Sobre o alçamento vocálico, veja Castro e Aguiar (2008b).

Caderno Seminal Digital Ano 19, no 19, V. 19 (Jan-Jun/2013) - ISSN 1806-9142 
O truncamento é um processo intra e interléxico alterativo de abreviação, que consiste na diminuição da estrutura da forma-base. Essa alteração pode espraiar-se também a nível semântico e se desdobra de várias formas. Denominado abreviação, redução, truncagem, truncação, de forma mais conhecida truncamento (ASSUMPÇÃO JÚNIOR, 1986). O truncamento é tido como um tipo de abreviação intencional, o que o distingue da apócope, sendo esta não intencional e inconsciente ${ }^{34}$. Araújo (2002) defende que o truncamento é um processo morfológico não linear ou não concatenativo, pela ausência de encadeamento, sendo substituído por supressão de elementos cujas formas truncadas são dissilábicas. Vilela, Godoy e Silva (2006) postulam que o truncamento é um fenômeno de encurtamento que gera formas com até três sílabas, como podemos verificar, a seguir.

\section{Menopá}

Disa: É qui tá quenti, i eu tẽu ũa agitaçãu da menopá i aí ela misturô aqui (risos).

HV2001: Menopausa é a interrupção fisiológica dos ciclos menstruais, devido à cessação de secreção hormonal dos ovários. Etim. men(o) + pausa.

[Menopá é o mesmo que menopausa.]

Vertença

${ }^{34}$ Conforme Assumpção Júnior (1986, p.120)

Caderno Seminal Digital Ano 19, no 19, V. 19 (Jan-Jun/2013) - ISSN 1806-9142 
Caderno Seminal Digital

Disa: pruquê lá é bom, lá tẽi nossas vertença, nóiz...

HV2001: Diversão, Substantivo feminino (1660); ato ou efeito de divertir-se; algo que serve para divertir. Etim.: latim tardio diversio, onis, digressão, diversão.

[Vertença é o mesmo que diversão.]

[Vertença é formado pelo processo de truncamento, com a perda de di- e modificação morfofonêmica, com o acrescentamento da consoante de ligação -t- e do sufixo -ença. Nesses dois itens, há um processo alterativo de abreviação, denominado truncamento.]

d) Itens lexicais sob a perspectiva da dinâmica histórica

O processo de formação dessas palavras deu-se em virtude da história externa e interna, por meio da influência de outras línguas. Neste caso, as línguas indígenas e as línguas africanas. Assumpção Júnior (1986, p. 108) denomina este processo de apropriação por transposição, em que há a adoção do "signo estrangeiro", preservada ou não sua estrutura fônica originária. Nestes casos, o autor diz haver adaptação, ou seja, um ajustamento da estrutura sonora da forma léxica ou aportuguesamento.

e) Inventário cujos termos constam de origem de línguas indígenas brasileiras

O território brasileiro, antes de sua ocupação, era formado por diversas nações indígenas, os Tupi ou Tupinambá. Em virtude da grande quantidade desses povos,

Caderno Seminal Digital Ano 19, no 19, V. 19 (Jan-Jun/2013) - ISSN 1806-9142 
no Século XVIII havia uma espécie de bilinguismo, em que os portugueses falavam tanto a língua materna quanto a língua geral Tupinambá ${ }^{35}$. Grande foi a contribuição das línguas indígenas para o português brasileiro. Não menos importante, a das línguas africanas, posto que chegaram ao Brasil, a partir do Século XVI, cerca de 18 milhões de escravos, principalmente de cultura banto e sudanesa. A contribuição africana para o léxico do português do Brasil resume-se a uma pequena quantidade de palavras. Entretanto, inúmeras formas foram conservadas, tanto de origem indígena quanto de origem africana, com algumas alterações morfofonêmicas, como ilustramos, a seguir.

\section{Tindi/Timbó}

Luzia: Tindi. Eu chamo timbó, maisi é porque quer chamar maisi o nome delié tindi.

HV2001: Etim.: Tupi timbó (1560). Designação comum a várias plantas das familias das leguminosas e das sapindáceas, cuja seiva é tóxica para peixes e, por isto, usada para pescar, variedade de cipó.

[Tindi e/ou timbó é uma fruta do cerrado bastante popular na região pesquisada. A forma variante tindi não foi encontrada no Houaiss.]

\section{Catolé, Piaçaba} ${ }^{35}$ Língua de contato resultante da base do português com o léxico/morfologia
Tupinambá.

Caderno Seminal Digital Ano 19, no 19, V. 19 (Jan-Jun/2013) - ISSN 1806-9142 
Caderno Seminal Digital

Neuza: Catolé, piaçaba, piaçaba...

HV2001: Substantivo feminino (1644); planta da família das palmas, espécie do gênero attalea frequentemente com frutos pequenos e oleaginosos, do Tupi päa'sawa'. Catulé, etim.: Tupi (1817): katu're.

[O catulé é uma fruta do cerrado bastante utilizada pelos sertanejos. A piaçaba ou piaçava é uma palmeira, cuja palma é utilizada para confeccionar vassouras, abanos, tapitis, entre outros utensílios, como também para fazer cobertura de casas.]

\section{Tucum}

Neuza:-Tucum, óliu di tucum.

HV2001: Substantivo masculino (1587); etimologia Tupi tukũ, designação de várias espécies de palmeiras, geralmente cepitóras, do gênero Ostracaryum e Bactris, nativas do Brasil e de países vizinhos, com frutos frequentemente comestíveis e folhas das quais se extraem fibras, conhecidas como fibras de tucum, tucunzeiro.

[Fruta do cerrado, bastante comestível e nutritiva, de sabor adocicado, que possui uma água dentro do coco. Assemelha-se ao coco da praia, sendo bem pequeno.]

\section{Caititu}

Aninha: Mar lá no Bals̃a eu teum bola de caititu, roda de caititu.

HV2001: O caititu é um instrumento utilizado na engenhoca de ralar a mandioca ou em outros produtos; peça principal, 
cilíndrica à qual se adaptam serrilhas metálicas e que tem uma das extremidades em forma de roldana, para através dela, se imprimir movimento de rotação. Substantivo masculino (1610); etim.: Tupi: tãite'tu, porco do mato.

\section{Cuim}

Aninha: Aí comprê ûa raçãu quíeu compru, é u quilu di cuím, vinti i cincu centavu.

HV2001: Substantivo masculino (1866); resíduo deixado pelo arroz, limpadura de arroz. Etim.: Tupi: cuí com nasalização -í > im em posição final.

[O cuim é uma palha de arroz triturada misturada aos grãos que, por serem muito pequenos, deixam de ser aproveitados, quando do processo de seleção do arroz. É bastante nutritivo, utilizado para alimentação de animais e como reforço alimentar para pessoas desnutridas.]

\section{Mamucapo}

Deci: Sim. É essiaqui, ó, qui é u mãmucapu.

HV2001: O mesmo que mamucaba ou mamucabo - trançado que liga o pano aos punhos da rede. Para Teodoro Sampaio, alteração de mambucaba, por sua vez, corruptela de mombucaba, furo, abertura, passagem, do tupi mombu'ka, o furo, o furado.

[O mamucapo é uma peça que ajuda a manter organizadas as linhas de fiar.] 
Caderno Seminal Digital

\section{Capuera}

Atividade-As capuera véa, pãiandu, pãia macachera.

HV2001: Etim.: Tupi; área de mato cuja vegetação anterior foi roçada e/ou queimada para cultivo ou outros fins.

[Capueira é o mesmo que mata não utilizada no plantio de roça por já estar desgastada.]

[Inventário de origem africana presente no falar local pesquisado.]

\section{Andu}

Atividade - Si eu subessi eu levu u andu pa siôra ,eu levú u andu i nun custa nada nãun.

HV2001: Etim.: quicongo, o mesmo que guandu, subarbusto ereto de até $3 m$ da família das leguminosas.

[Andu é uma espécie de feijão considerada bastante medicinal nessa região.]

\section{Canga}

Deci: Essa peça aí é ũa canga, pá botá nu boi.

HV2001: A canga é uma peça de madeira usada para prender as juntas de bois. De etim. quiconga, africana.

f) Itens lexicais sob a perspectiva da dinâmica sociocultural: processos criativos de formação do léxico

O sertanejo, ao dispor de certa quantidade de elementos que competem paradigmaticamente, seleciona os que lhe parecem 
mais convenientes, influenciado, principalmente, por fatores semânticos e pragmáticos. Esses processos criativos de formação do léxico nem sempre são coincidentes com os mesmos de derivação e composição que se apresentam nas gramáticas tradicionais. No entanto, as gramáticas translinguísticas trazem maiores possibilidades de identificação deles.

g) Inventário com processos de derivação não tradicional

Neste inventário, apresentamos os processos de derivação não tradicional. Posto que alguns afixos apresentam forma peculiar específica da região, o item lexical é geralmente uma forma recuperada/presenvada, em função do caráter tanto conservador quanto inovador.

\section{Apusentação}

Conceição: Eu vim, demorei essi' zôtu... essir dia pá arrumá essir documẽntu dessa apusentaçãu ...

HV2001: Etim.: aposentar + ação; foi acrescentado o sufixo -ção formador de substantivo (1871).

[Apusentação é o mesmo que aposentadoria.]

[Processo de sufixação, com o acréscimo do sufixo -ção.]

\section{Malaquenta}

Natividade: Agenti pranta poquin, puque a coiza tá poca, toda malaquenta véa toda duenti véa, num é? 
HV2001: Malacafenta, adjetivo (1899), quem está com malaca, doente, enfermiço. Etim. malaca + ento, com elemento de ligação arbitrário 'f' mais o sufixo - enta, que está caracterizando a forma como um adjetivo.

[Processo de sufixação, com o acréscimo do sufixo -enta.]

\section{Dicumê}

Aninha: Mar u mais é tudo junto i teu pena quandu eli tá lá só, pois eli é quem faz u dicumer.

[De-Comer, que se transformou em dicumê; o mesmo que comida.]

[No item lexical dicumê há o processo de derivação imprópria, processo de substantivação, formado pela junção da preposição de com o verbo comer, formando um substantivo comum.]

h) Categoria de itens lexicais idiossincráticos

Nesses processos da dinâmica léxica, percebemos que há inovação pela mudança semântica de um termo, o qual adquire propriedades significativas especiais, próprias de cada pessoa ou de grupos específicos de pessoas, ou seja, idiossincráticas. Essas propriedades são motivadas, dentre os muitos fatores, pelo contexto sociocultural local. A forma adquire novo significado, sem, no entanto, perder totalmente o significado anterior do vocábulo, além de que, não necessariamente há modificação na forma. 


\section{Amigá}

Mudubim: Num gostu di casá fia mia, nãu. Gostu di vê é si amigá pá si batê na vida delis.

HV2001: O verbo (Século XV) significa ligar- (se) por mancebia, tornar-(se) amante de. Etimologia: amigo + ar.

[Amigá, viver maritalmente, sem o enlace matrimonial do casamento civil ou religioso.]

[Derivado do substantivo amigo, possui conotação meio pejorativa nas comunidades rurais.]

\section{Trisca}

Neuza: - Aqui era tãu difiçu, agenti cumia du trisca, du sal, é.

HV2001: Substantivo masculino (1560). Ato ou efeito de triscar; etimologia: gótico thriskan, debulhar, trilhar.

[Pequena quantidade com que era utilizado o sal, pela sua escassez, até o início do Século XX.]

[Há o processo de substantivação do verbo triscar, motivado semanticamente pela situação de carência do uso do sal até meados do Século XX.]

[Nestes quatro itens lexicais amigá, cercado, cuberta, trisca houve recategorização de função morfossintática dos termos, ou seja, a atribuição de uma nova categoria linguística diversa da já existente, comumente denominada por derivação imprópria. Assumpção Júnior (1986) denomina-os recategorização, derivação imprópria, transposição, translação e conversão. Este 
Caderno Seminal Digital

processo é bastante recorrente em diversas línguas, principalmente no português.]

\section{Pratu}

Aninha: Saía quatu hora, cum deis pratu de cocu i dois litro di azeiti na cabeça.

HV2001: O prato (1485), nas balanças antigas é um tipo de recipiente em forma de prato ou tigela em que são colocados os pesos e o que se quer pesar; unidade de medida para cereais.

[Na região pesquisada, o prato era muito usado como uma unidade de medida para cereais representada por duas medidas em caneca de flandre.]

\section{Incosto}

Mudubim: Tô pricisandu dum incostu.

HV2001: Substantivo masculino (1562), aquilo que serve de amparo, de proteção, de arrimo. Etimologia de encostar cost(i); do latim costa,ae, costela, lado, flanco.

[Incosto, na linguagem dos sertanejos pesquisados, é o mesmo que aposentadoria.]

\section{Assunta}

Mudubim: Ai, dona Célia, é bom dimais, purquê u seu fiu assunta, u meu assunta...

HV2001: O verbo assuntar (1872) é o mesmo que prestar atenção, reparar; pensar longamente, refletir, olhar, ver, verificar com detalhes; apurar. Etim.: assunto + ar. latim sum, 
Caderno Seminal Digital

praesumo,is praesumpsi, praesumptum,ere, tomar antes do tempo; fazer juízo antecipado, conjecturar, suspeitar, presumir.

[Assuntar é o mesmo que observar, analisar, ponderar sobre os estados de coisas.]

\section{Papa-Fogo}

Zezão: U papa fogu.

HV2001: isqueiro tosco.

[Papa-Fogo é um instrumento rudimentar bastante utilizado para acender um fogo, isqueiro rudimentar, tosco. Substantivo composto masculino.]

\section{Tramóia}

Deci: Eu, da mĩa lĩnguagi antiga, chamava era tramóia...

HV2001: Etim.: espanhola (1679), tramoya é um tipo de renda paulista, de pontos largos.

[Tramóia é um tipo de renda feita manualmente sem o uso de nenhum instrumento.]

[Esses três itens lexicais assunta, papa-fogo e tramoia passam por um processo de reativação, o qual consiste na retomada de uma forma ou significado que tenham caído em desuso, por terem sido superados por outros (escuta, presta atenção, observa; renda, varanda), principalmente nas áreas urbanas, onde o ambiente linguístico é mais propenso à dinamicidade. Entretanto, cremos nunca ter caído em desuso na zona rural pesquisada, o que nos faz pensar num processo de retenção 
dessas formas. Os termos são reativados ao nível do léxico local, pois parecem obsoletos nas demais regiões em que 0 português é falado.]

\section{Dirmartiá}

Zezão: Aí cumeçô dirmartiá a coluna.

HV2001: Verbo desmantelar (1648); fazer ruir ou ruir, fazer vir ou vir abaixo; descompor- (se) [algo] de maneira que deixe estar feito, montado, coeso, unido ou equilibrado; desagregar- (se), desmanchar- (se), desestruturar- (se); causar transtornos a; desarranjar, desorganizar, perturbar. Etimologia francesa: dèmanteler (1563).

[Dismartiar é o mesmo que desmantelar, adoecer da coluna.]

[Em dirmartiar há uma mistura das formas desmarcar (dismantelar), sair fora dos limites, com desmantelar (dismantelar > dismantiar), havendo a junção dos dois termos com todos os processos fonológicos de adequação, como a assimilação e supressão de fonemas para a formação do novo item, sem, no entanto, haver prejuízo do significado das duas formas componíveis.]

\section{Furmina}

Ciçu: Tẽi... Vixi! A penađia tá lá reservada, chega furmina!

HV2001: Etim.: latina; formigar é o mesmo que ter em abundância, pulular, fervilhar (1562). 
[Furmina é o mesmo que existir em quantidade quase que excessiva.]

[Há rotacismo do $/ / /$ em $/ r$ / no verbo fulminar quanto à alternância do vocábulo "formigar" com a assimilação do /g/ > /n/, ou ainda pode haver uma fusão morfológica e semântica das palavras formigar e fulminar, em virtude da semelhança entre as mesmas, tanto na forma quanto no significado. Em furmina, a junção de formiga com fulmina porta a ideia de grande quantidade de coisas/seres.]

\section{Pècurei}

Conceição: Não, eu fui lá, ela nũm tava. Aí eu pecurei a ela.

HV2001: Etim.: latina praecunto, as, avi, atum, are; percontare; Século XV perguntarrom, indagar; etim.: latina procuro, as, avi, atum, are, tratar com cuidado de negócios alheios, administrar, governar, olhar por, presidir, fazer expiações.

[Pècurei refere-se à alternância do vocábulo procurar, tendo em vista outras realizações em que ocorrem as seguintes alternantes: procurei > percurei > pecurei; ou ainda perguntei > peguntei > pecuntei > pecurei, assim, há uma fusão morfológica e semântica das palavras procurar e perguntar, em virtude da semelhança entre elas tanto na forma quanto no significado. Pècurei é o mesmo que perguntei.]

[Em palavras como dismartiar, furmina e pècurei ocorre a composição (acoplação) ou imbricação que é um tipo de conjunção em que há a formação de uma forma léxica pela 


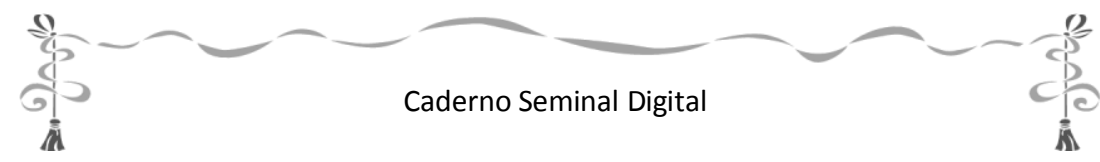

junção de pelo menos duas outras palavras com prejuízo da forma fônica das palavras preexistentes. Assumpção Júnior (1986), baseado no termo francês acronyme, dá o nome de acronimização. Por acumular componentes de várias palavras recebe o nome de portemanteau (francês).]

i) Itens lexicais com especificação de significado

Nesses itens lexicais, os fatores motivadores da mudança/alteração, são os semântico-pragmáticos. Um determinado item passa a ter um nome mais específico, motivado por uma relação de semelhança metafórica e metonímica entre este item e outro já existente. O novo nome e $o$ anterior se relacionam por algum tipo de contiguidade conceptual (relação metonímica) e ou por uma relação existente entre duas realidades semelhantes, com a mesma forma (relação metafórica).

\section{Fuzil}

Zezão:-Aqui éa pedra, aqui é u fuziu.

HV2001: Substantivo masculino (Século XIV), isqueiro de chifre de boi; binga. Etim do latim vulgar focile derivado do latim focus, i, fogo; providência abreviada de facilis petra, pedra de fogo.

[O fuzil, nesse contexto, é parte do papa-fogo ou binga que, em contato com a pedra, aciona a faísca que acende o algodão, ou pavio. Usado para acender o fogo, cigarros, ou cachimbos.]

[Há relação i) de semelhança (metafórica) entre o instrumento mais específico que aciona a faísca, o qual é cunhado fuzil, e a

Caderno Seminal Digital Ano 19, no 19, V. 19 (Jan-Jun/2013) - ISSN 1806-9142 
Caderno Seminal Digital

arma que leva a mesma denominação, ou seja, o instrumento que aciona a faísca; ii) de contiguidade (metonímica): o instrumento em sié denominado com o nome da arma inteira.]

\section{Artifiçu}

Zezão: - Chamava papa-fogu. Di primero, di primero a lingagi era artifiçu.

HV2001: Etim.: latim artificium,ii, arte, arte mecânica, trabalho artístico, conhecimento técnico, ofício, ocupação, astúcio, habilidade, aptidão, ciência, teoria, sistema.

[Artifício é um dos nomes que recebe o instrumento papa-fogo ou binga. Informalmente, isqueiro; artefato. O dicionário Houaiss registra este item como típico do Rio Grande do Norte, da Bahia e de Goiás. No entanto, é um termo bastante recorrente na zona rural da região pesquisada.]

[Há uma relação metonímica da significação de artefato, com o artefato específico fuzil.]

\section{Penadĩa}

Ciçu: Têi.. Vixi! A penadĩa tá lá reservada, chega furmina.

HV2001: Empenado, adjetivo (Século XIII) adornado com penas; emplumado. Etim.: do particípio de empenar, pen(i), elemento composto antepositivo, do latim, penna, ae, asa, o que serve para voar; asa (das abelhas); pena grande das asas ou da cauda das aves, em oposição a pluma. 
[Penađia, penadinha é o mesmo que galinha, frango, capão; forma diminutiva de "penada" que por sua vez já é uma forma truncada de empenada.]

[Há uma relação de contiguidade da característica geral da espécie ave para denominar um tipo específico de ave, a galinha. Também aqui há uma recategorização do adjetivo para um substantivo (denominada derivação "imprópria" no português tradicional) em que essa conversão, nos termos de Aikhenvald (2007), carrega consigo a flexão de grau diminutivo.]

\section{Congresso}

Mudubim: As veiz um homi até di congressu...

HV2001: Substantivo masculino (1510); ato de conversar, de dialogar, entrevista, conversação, conferência. Etim.: do latim congressus, us, trato, comércio, relação, entrevista, conferência, conversação.

[De congresso significa, neste contexto, de responsabilidade, de caráter.]

[Há uma relação de semelhança e contiguidade entre as pessoas que representam o congresso, as quais o falante imagina que sejam de respeito, de boa reputação, e o sujeito a quem ele tenta qualificar.]

\section{Tribuna}

Mudubim: Ali têi muita tribuna, mĩa rimã, eu vô lhi dizê, nói ramu lhi jogá lá dentu. 


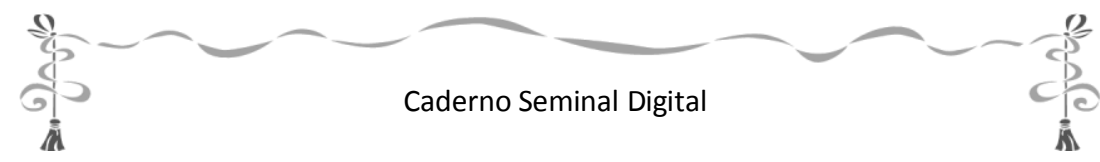

HV2001: Substantivo feminino (Século XV); capacidade de falar e expressar-se com desenvoltura em público; eloquência. Etim. do latim tardio tribuna,ae, púlpito do tribuno.

[Tribuna, neste contexto, significa confusão, negócios duvidosos, "rolos".]

[Há uma relação de contiguidade e semelhança entre tribuna e o que pode ocorrer durante o momento em que se esteja nesse local (por exemplo, as típicas discussões parlamentares) ou exercendo o ato de falar/discutir. Desta forma, o falante se utiliza conceptualmente desta relação para nomear os substantivos que têm relação de significado com congresso (pessoa culta, respeitosa) e tribuna (confusão).]

\section{CONSIDERAÇÕES FINAIS}

Ao realizar esta análise, entendemos que cultura e linguagem estão ligadas por meio de um relacionamento estrutural, pois a cultura é o conjunto dos padrões de comportamento, atitudes, crenças, costumes e saberes que são inerentes ao indivíduo e ao meio social em que ele está inserido. Intrinsecamente ligada à cultura está a história, cujos eventos marcam a cultura e, por conseguinte, a língua dos sujeitos que as vivenciam. Logo, a cultura e a história "influenciam" o nosso pensamento, a forma como recortamos, como compreendemos, como categorizamos e classificamos as coisas, como propuseram Sapir (1985) e Worf (1988), e são esses elementos que constituem a essência do

Caderno Seminal Digital Ano 19, no 19, V. 19 (Jan-Jun/2013) - ISSN 1806-9142 
Caderno Seminal Digital

î.

que é expresso pela língua. Significa dizer que por meio da língua são transmitidas as experiências, que são uma representação de mundo. Essa representação de mundo se dá, principalmente, através do léxico. Portanto, os itens lexicais são resultantes da memória conceptual, marcada pelo seu processo histórico (GIVÓN, 2001).

Com base nesses pressupostos, fizemos algumas reflexões preliminares acerca dos processos na dinâmica do sistema lexical do sertanejo balsense. Os exemplos se apresentam em mais de um dos níveis e não há uma delimitação precisa entre as categorias morfológicas e as semânticas, posto que houve não uma categorização tipológica, mas uma classificação, feita mais por necessidade didática, por ser difícil estabelecer uma fronteira entre a dinâmica sistemática, a histórica e a sociocultural dos processos dinâmicos desse léxico.

\section{REFERÊNCIAS}

AIKHENVALD, A. (2007). Typological distinctions in word-formation. InSHOPEN, T. Language, Typology and Syntactic Description. V. III, 2. Ed. Cambridge University Press.

ARAÚJO, Gabriel (2002). Truncamento e reduplicação no português brasileiro. Revista de Estudos da Linguagem. Belo Horizonte, v.10, n.1, p. 61-90, jan./jun.. ASSUMPÇÃOJÚNIOR, A. P. (1986). Dinâmica Léxica Portuguesa. Rio de Janeiro: Presença.

CABRAL, M. doS. C. (1992). Caminhos do Gado: conquista e ocupação do Sul do

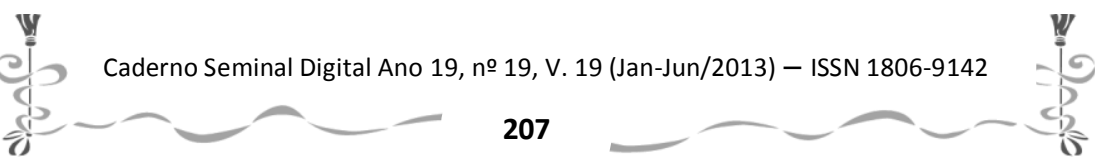


A

Maranhão. São Luís:SIOGE.

CASTRO, M. C. D. de. Descrição histórica das vogaisna fala do sertanejo da região de Balsas-MA. Universidade Federal de Goiás (Dissertação de Mestrado), 2008, $184 f$.

CASTRO, M. C. D. de. AGUIAR, M. S. de (2008b). Oalçamento e o abaixamento vocálicos no dialeto da região do Gerais de Balsas. Revista Signótica. Goiânia, v. 19, p. 277-298.

GIVÓN, T. (2001).Syntax: An Introduction. V.1. Amsterdam; Philadelphia:John Benjamin.

HOUAISS, A. Villar, M. deS. (2001). Dicionário Houaiss da Língua Portuguesa. Rio de Janeiro: Objetiva.

RIBEIRO, D. (1986). Os índios e a civilização. 5. ed. Petrópolis: Vozes.

RIBEIRO, F. de P. (2002 [1815; 1819; 1819]). Memórias dos sertões maranhenses. Reunidas aos cuidados de Manoel de Jesus Barros Martins. São Paulo: Editora Siciliano.

RODRIGUES,A. D. (1985). Línguas brasileiras: para o conhecimento das línguas indígenas. São Paulo: Loyola, 1986.

SAPIR, E. Selected Writings in Language, Culture, and Personality. London: University ofCalifornia Press Ltda..

VILELA, A. C., GODOY, L, SILVA, T. C. (2006). Truncamento no português brasileiro: para uma melhor compreensão do fenômeno. Revista Estudos da Linguagem. Belo Horizonte, v.14, n.1, p. 149-174, jan./jun.

WHORF, B. L Science and linguistics. In: SMOLNSKI. F. (1988). Landmarks of American language and linguistics. Washington D.C. Bureau of Educational and Cultural Affairs, p. 31-38.

Caderno Seminal Digital Ano 19, no 19, V. 19 (Jan-Jun/2013) - ISSN 1806-9142 